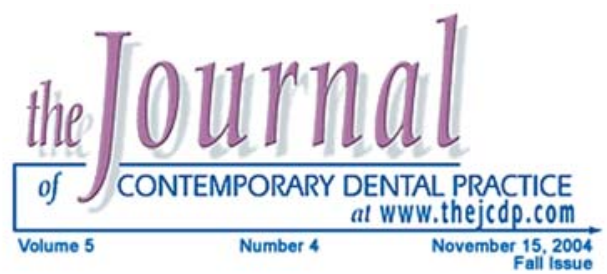

\title{
An In Vitro Evaluation of the Diagnostic Quality Ultra-Speed Versus Insight Intraoral Dental Film
}

Thomas Schiff, DMD; Brandy Egan Solomon, DDS

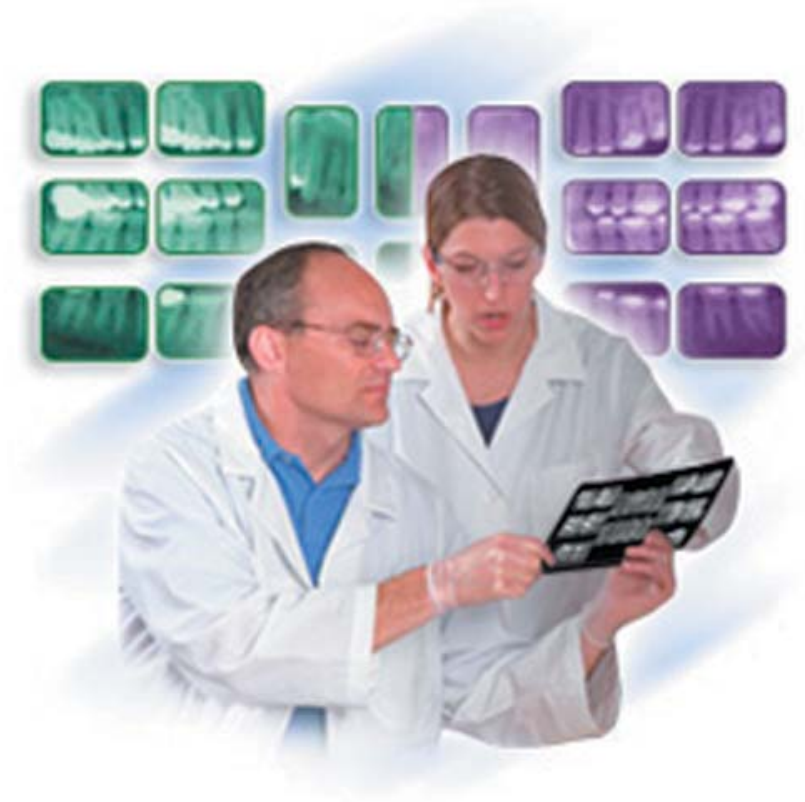

Abstract

Twelve sets of FMS (full mouth survey) radiographs were taken by California licensed radiology technicians. Ten of the sets of FMS radiographs were taken using Ultra-Speed "D" film on the left side of the patient and Insight "F" speed film on the right side of the patient. The remaining two sets of films were taken using Insight Film on both sides of the patient to act as a control. Ten faculty members of the Diagnostic Department were asked to evaluate the twelve sets of FMS radiographs and report whether they had a preference for the right side, left side, or no preference. Criteria for preference were diagnostic ability and clarity of the films. The results of the study showed a preference for the right side $(65.7 \%)$, which was imaged with Insight Film, compared to the left side (34.3\%), which was imaged with Ultra-Speed Film.

Keywords: Ultra-Speed (D-speed), InSight (F-speed)

Citation: Schiff T, Solomon BE. An In Vivo Evaluation of the Diagnostic Quality Ultra-Speed Versus Insight Intraoral Dental Film. J Contemp Dent Pract 2004 November;(5)4:050-057.

(C) Seer Publishing 
Introduction

Historically, the improvement of silver halide technology has been limited by a crucial tradeoff between film speed and image quality. This has been true for both photographic and x-ray film. ${ }^{1}$ In dentistry, the trade-off has had practical consequences: higher quality dental x-ray films have typically required longer exposure times. While these films provide excellent imaging characteristics, their longer exposure times increases both radiation exposure levels to patients and the likelihood of blurring from patient movement.

The goal of diagnostic imaging scientists has been to eliminate this trade-off by developing $x$-ray film which maintains required imaging characteristics, including sharpness, contrast, and density, while at the same time permitting a reduction in exposure times. ${ }^{1,2}$ To this end, in 2000 the Eastman Kodak Company released a new dental x-ray film, Kodak InSight Intraoral Dental Film, which the company claimed would allow dentists to reduce exposure time by $60 \%$ as compared to their D-Speed film, Kodak Ultra-Speed Intraoral Film.

Since the introduction of InSight Film, however, many dentists have continued to use D-Speed products, due in part to the persistent belief that faster films require degradation in image quality. To address this issue, a study was designed to compare the in vivo imaging characteristics of InSight and Ultra-Speed Film.

\section{Methods and Materials}

Twelve sets of FMS radiographs were taken by California licensed radiology technicians. Ten of the sets of FMS radiographs were taken using
Ultra-Speed Film on the left side of the patient and InSight Film on the right side of the patient. The remaining two sets of films were taken using InSight Film on both sides of the patient to act as a control. Each film was exposed using 15 $\mathrm{mA}, 80 \mathrm{KvP}$, and the appropriate exposure time for the film speed (12 impulses for anterior films and 18 impulses for posterior films when using InSight film (F-speed), or 24 impulses anterior films and 36 impulses for posterior films when using Ultra-Speed film (D-speed.) Each set of Full Mouth Series was exposed while using a Rinn XCP positioning device. The film sets were viewed using a light box in a room with dim ambient lighting.

We then asked ten general dentists (teaching faculty at the University of the Pacific) to evaluate the FMS looking for differences in diagnostic quality of the films. The evaluators were not told the FMS radiographs were taken with different types of films, they were asked only to compare the right side of the FMS to the left side and select which side of the FMS they had a preference for, if any.

The data was collected and submitted for statistical analysis using a normal approximation of the binomial expansion with correction for continuity.

\section{Results}

Table 1 displays the data collected with analysis from the study.

Cases number three and eight were excluded because they were the controls (both sides of FMX taken with the same speed film $\left(\right.$ Insight $\left.^{\circledR}\right)$.

\begin{tabular}{|c|c|c|c|c|c|}
\hline \multicolumn{7}{|c|}{ Table 1. } \\
\hline Case & $\begin{array}{c}\text { Right side } \\
\text { preferred }\end{array}$ & $\begin{array}{c}\text { Left side } \\
\text { preferred }\end{array}$ & $\begin{array}{c}\text { No } \\
\text { preference }\end{array}$ & Sign & $\begin{array}{c}\text { Needed for } \\
\text { p=.05 }\end{array}$ \\
\hline 1 & 3 & 6 & 1 & .254 & \\
\hline 2 & 6 & 3 & 1 & .254 & approx. 32 \\
\hline 3 & 1 & 4 & 5 & .188 & approx. 10 \\
\hline 4 & 9 & 0 & 1 & .002 & \\
\hline 5 & 3 & 5 & 2 & .363 & approx. 40 \\
\hline 6 & 7 & 1 & 2 & .035 & \\
\hline 7 & 0 & 1 & 9 & .500 & \\
\hline 8 & 2 & 3 & 5 & .500 & \\
\hline 9 & 4 & 1 & 5 & .188 & approx. 10 \\
\hline 10 & 5 & 3 & 2 & .363 & approx. 40 \\
\hline 11 & 4 & 2 & 4 & .344 & approx. 32 \\
\hline 12 & 5 & 2 & 3 & .227 & approx. 30 \\
\hline
\end{tabular}


Of the 100 pairs that remained after the controls were removed, the practitioners favored the right side (imaged with Insight Film) for 46 of the pairs; the practitioners favored the left side (imaged with Ultra-speed Film) for 24 of the pairs; and the practitioners had no preference for one side over the other for the remaining 30 pairs.

If we remove the case where the practitioners did not show a preference for either side over the other, we are left with 70 pairs.

Of the remaining 70 pairs, 46 practitioners $(65.7 \%)$ favored the right side (imaged with InSight Film) and 24 practitioners (34.3\%) favored the left side (imaged with Ultra-speed Film).

The test used was the normal approximation of the binomial expansion with correction for continuity. The hypothesis that there is no preference for either side (50:50) is rejected at $p=.012$, two-tailed.

\section{Discussion}

This study found $65.7 \%$ of the practitioners showed a preference for the images that were taken using the InSight film (F-speed), the remaining $34.3 \%$ of the practitioners showed a preference for the images that were taken using Ultra-speed film (D-speed). We are left to conclude with some practitioners there is actually a preference for the diagnostic quality of the faster speed film. This is contrary to the widely held belief of practicing professionals that slow speed (D-speed) film is of a higher diagnostic quality than that of the high speed film (F-speed).

The films were all developed using fresh developing solutions and an automatic processor in an attempt to standardize the developing of the films as to avoid introducing any differences in film quality due to processing differences.

Each practitioner viewed the films using the same light box and ambient room lighting in an attempt to avoid introducing any differences due to lighting changes.
All reviewers of films are qualified diagnosticians on the clinical faculty at the University of the Pacific; no specific pre-calibration was done to ensure an unbiased result.

The significance of the results is high quality radiographs with a $50 \%$ reduction in the radiation exposure level to the patient.

Although the results of this study proved to give statistically significant results, it may be beneficial to conduct a second study with a larger sample size.

The goal of dental radiology is to provide useful diagnostic information to the dental care provider while minimizing the radiation exposure to the patient. Dental radiology should use exposure to radiation following the principles of ALARA (As Low As Reasonably Achievable), which recognizes the possibility that no matter how small the dose there may be some effect. ${ }^{5}$ 


\section{References}

1. Eachus RS, Marchetti AP, Muenter AA. The photophysics of silver halide imaging materials. Annu Rev Phys Chem. 1999;50:117-44.

2. Busch HP, Busch S, Decker $\mathrm{C}$, et. al. [Image quality and exposure dose in digital projection radiography] Rofo. 2003 Jan;175(1):32-7. German.

3. Sheaffer JC, Eleazer PD, Scheetz JP, et. al. Endodontic measurement accuracy and perceived radiograph quality: effects of film speed and density. Oral Surg Oral Med Oral Pathol Oral Radiol Endod. 2003 Oct;96(4):441-8.

4. Farman TT, Farman AG. Evaluation of a new $F$ speed dental $X$-ray film. The effect of processing solutions and a comparison with D and E speed films. Dentomaxillofac Radiol. 2000 Jan;29(1):41-5. Erratum in: Dentomaxillofac Radiol 2000 Mar;20(2):131.

5. International Commission on Radiological Protection: Radiation protection, ICRP Publ 60, 1990.

(Note: Kodak, InSight, and Ultra-Speed are trademarks.)

\section{About the Authors}

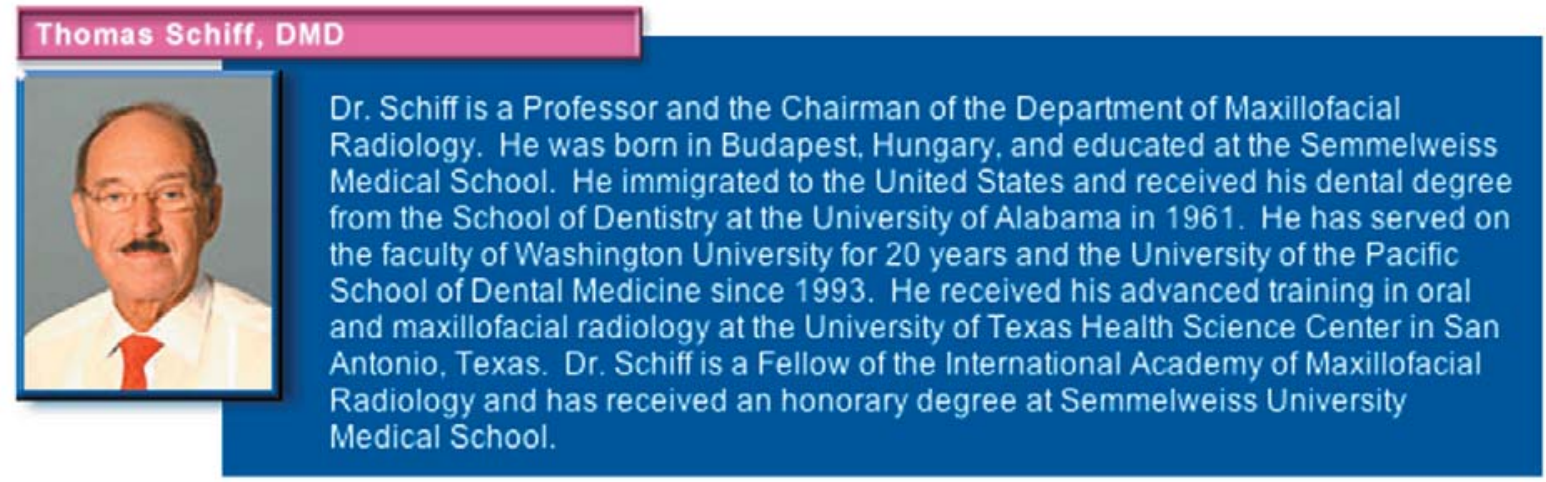

Brandy Egan Solomon, DDS

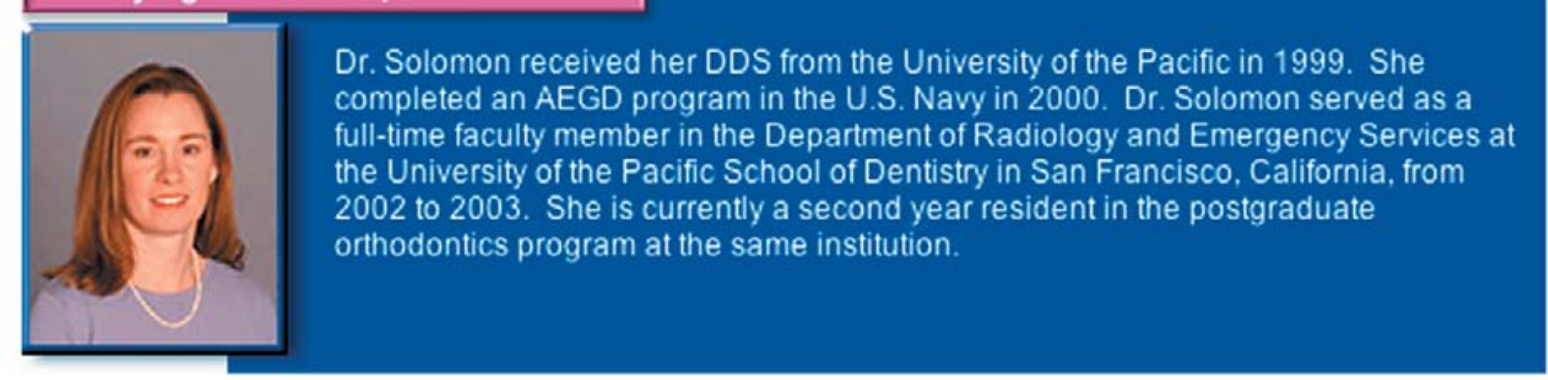

